\title{
A Comparison of Two Novel Non-Ferrous Metal Recovery Equations: Development, Similarity and Industrial Significance
}

\begin{abstract}
E.J. GRIMSEY
The recovery of non-ferrous metals in oxidative sulfide smelting and converting processes and within reductive oxide smelting processes has been previously analyzed using two similar equations which express recovery in terms of iron transfer and a distribution coefficient. A detailed comparison will show that the equations are mathematically identical but with one equation validated only for constant distribution coefficients. The wider applicability of the equation and implications for optimization of metal recovery are discussed.
\end{abstract}

https://doi.org/10.1007/s11663-021-02238-y

(c) The Author(s) 2021

TWO metal recovery equations which conveniently express non-ferrous metal recovery in terms of iron transfer and a readily measured distribution coefficient will be compared. The equation was first used by Grimsey ${ }^{[1-5]}$; a similar equation was subsequently used by Jones et al. ${ }^{[6-11]}$ However, the initial equation has never been discussed by Jones et al. and has only been referenced once $^{[8]}$ by these authors. The development of the two equations, their relationship, and their relevance will be considered here. They will be referred to, respectively, as the Grimsey and Jones equations in this discussion.

Sulfur and iron are the major impurities within sulfide mineral concentrates which contain valuable nickel, copper and cobalt. The impurities are removed by oxidation of matte (molten sulfide) with air, with sulfur reporting to gas as $\mathrm{SO}_{2}$ and iron reporting to molten silicate slag as iron oxide. It is well understood that the recovery of non-ferrous metals to liquid sulfide matte decreases as more iron impurity is oxidized and transferred to slag since non-ferrous metal is transferred along with it. The important relationship between non-ferrous metal recovery and iron transfer can be described by a novel metal recovery equation using a distribution coefficient, as reported by Grimsey, ${ }^{[1-5]}$ namely:

$$
R_{M e}=\frac{1-y}{1-y+\frac{y}{K_{M e}^{\prime}}}
$$

$R_{M e}$ represents fractional metal recovery to matte, $y$ represents the fraction of iron impurity reporting to

E. J. GRIMSEY is an Emeritus Professor with Curtin University, Perth, WA, 6102, Australia. Contact e-mail: e.grimsey@curtin.edu.au Manuscript submitted April 26, 2021; accepted May 26, 2021.

Article published online July 9, 2021. the slag and $K_{M e}^{\prime}$ represents a distribution coefficient defined as:

$$
K_{M e}^{\prime}=\frac{[M e \mathrm{pct}]}{(\text { Me pct })} \frac{(F e \mathrm{pct})}{[F e \mathrm{pct}]}
$$

where $[M e p c t]$ and (Mepct) represent the respective percents of non-ferrous metal $\mathrm{Me}$ (e.g., $\mathrm{Ni}, \mathrm{Cu}, \mathrm{Co}$ ) in matte and slag and $[\mathrm{Fepct}]$ and (Fepct) represent the respective percents of iron. The fact that these four concentration terms could be grouped within a single distribution coefficient to succinctly describe metal recovery was not initially obvious. An iron mass balance, previously unpublished, led to this recognition.

Consider, for example, the distribution of iron and any other metal $M e$ within a non-ferrous matte/slag sulfide smelting system. If fraction $y$ of iron reports to slag, the mass of Me in slag per ton of iron is given by $\frac{(M e p c t)}{(F e p c t)} y$ and the mass of $M e$ in matte per ton of iron is given by $\frac{[M e p c t]}{[F e p c t]}(1-y)$. Total $M e$ is $\frac{(M e p c t)}{(F e p c t)} y+$ $\frac{[M e p c t]}{[F e p c t]}(1-y)$ and the fractional recovery to matte $\left(R_{M e}\right)$ can be expressed as

$$
R_{M e}=\frac{\frac{[M e \mathrm{pct}]}{[F e \mathrm{pct}]}(1-y)}{\frac{[M e \mathrm{pct}]}{[F e \mathrm{pct}]}(1-y)+\frac{(M e \mathrm{pct})}{(F e \mathrm{pct})} y}
$$

Division throughout by $\frac{[M e p c t]}{[F e p c t]}$, with rearrangement, gives Eq. [1]:

$$
R_{M e}=\frac{(1-y)}{(1-y)+\frac{(M e \mathrm{pct})[\mathrm{Fe} \mathrm{pct}]}{[M e \mathrm{pct}]}\left[\frac{F e \mathrm{pct})}{(1-3}\right.}=\frac{1-y}{1-y+\frac{y}{K_{M e}^{\prime}}}
$$

Equation [1] is simply a unique expression of the mass balance and hence must be true over the full range of 
iron transfer $(y)$ relevant to a separation process. The equation places no constraint on the value of the distribution coefficient $K_{M e}^{\prime}$ but will only be useful for process control and monitoring if $K_{M e}^{\prime}$ remains constant or changes in a predictable manner with change in $y$. During nickel sulfide converting, for example, $K_{C o}^{\prime}$ was found to have a constant value, ${ }^{[1-5]} K_{N i}^{\prime}$ to have a constant value after discounting entrainment, ${ }^{[5]}$ and $K_{C u}^{\prime}$ to have a value which varied as a function of $\log [\mathrm{Fe}$ pct]..$^{[3,5]}$

During sulfide converting the transfer of iron to slag occurs in multiple stages rather than in a single stage as defined by Eq. [1]. However, the equation can be expanded for multiple stages. If slag is taken off in two stages, for example, in which iron fraction $y_{1}$ is removed in the first stage and iron fraction $y_{2}$ in the second stage, where $y_{1}$ and $y_{2}$ are fractions of the original iron in matte, then Eq. [1] expands to give:

$$
R_{M e}=\frac{\left(1-y_{1}\right)\left(1-y_{1}-y_{2}\right)}{\left(1-y_{1}+\frac{y_{1}}{K_{M e}^{\prime}}\right)\left(1-y_{1}-y_{2}+\frac{y_{2}}{K_{M e}^{\prime}}\right)}
$$

The general equation for $n$ stages, originally verified by Dr Mark Lucas, ${ }^{[12]}$ takes the form:

$$
R_{M e}=\prod_{i=1}^{n}\left(\frac{1-\sum_{j=1}^{i} y_{i}}{1-\sum_{j=1}^{i} y_{j}+\frac{y_{i}}{K_{M e}^{\prime}}}\right)
$$

Significantly, because the single stage Eq. [1] and multistage Eq. [6] are both an expression of a mass balance, they would be applicable to any two-phase separation process, whether metallurgical or otherwise, and could provide valuable relationships for process monitoring and control when the transfer of one species is linked to the transfer of another such that $\mathrm{K}_{\mathrm{Me}}^{\prime}$ has a reproducible value.

Jones and co-workers subsequently developed and utilized an equation to describe the recovery of non-ferrous metal (Co, Ni, Cr) and PGM's within liquid ferroalloys produced during the smelting of oxides with carbonaceous reductant ${ }^{[6,8-11]}$ and for converting of alloy with oxygen. ${ }^{[7]}$ The equation expressed the fractional recovery of non-ferrous metal $\left(R_{M e}\right)$ in terms of the fractional recovery of iron $\left(R_{F e}\right)$ and a constant distribution coefficient $\left(K_{\gamma}\right)$, according to:

$$
R_{M e}=\frac{K_{\gamma} R_{F e}}{1-\left(1-K_{\gamma}\right) R_{F e}}
$$

In contrast to the first approach, in which the recovery equation was identified directly from a mass balance, the Jones equation was developed, ${ }^{[6,9]}$ by initially using thermodynamics to identify a distribution coefficient that would remain constant throughout the separation process. Mole balances and recovery equations based on moles, were then substituted within the distribution coefficient and rearranged to derive Eq. [7].

The development was illustrated using the distribution of cobalt and iron within ferroalloy after carbonaceous reduction of oxides in the presence of slag. Under this scenario, the final distribution was reasonably assumed to be controlled near equilibrium by a divalent metal/iron exchange reaction, according to:

$$
\mathrm{CoO}(\text { slag })+\mathrm{Fe}(\text { alloy }) \leftrightarrow \mathrm{Co}(\text { alloy })+\mathrm{FeO}(\text { slag })
$$

for which:

$$
\begin{aligned}
K_{8} & =\frac{a_{\mathrm{Co}}}{a_{\mathrm{CoO}}} \frac{a_{\mathrm{FeO}}}{a_{\mathrm{Fe}}}=\left(\frac{\gamma_{\mathrm{Co}} x_{\mathrm{Co}}}{\gamma_{\mathrm{CoO}} x_{\mathrm{CoO}}}\right)\left(\frac{\gamma_{\mathrm{FeO}} x_{\mathrm{FeO}}}{\gamma_{\mathrm{Fe}} x_{\mathrm{Fe}}}\right) \\
& =\left(\frac{\gamma_{\mathrm{Co}}}{\gamma_{\mathrm{Fe}}} \frac{\gamma_{\mathrm{FeO}}}{\gamma_{\mathrm{CoO}}}\right)\left(\frac{x_{\mathrm{Co}}}{x_{\mathrm{CoO}}} \frac{x_{\mathrm{FeO}}}{x_{\mathrm{Fe}}}\right)
\end{aligned}
$$

where $a$ is activity relative to liquid standard state, $\gamma$ is activity coefficient and $x$ is mole fraction. Given the chemical similarity of iron and cobalt, $\gamma_{C o} / \gamma_{F e}$ within the alloy and $\gamma_{\mathrm{FeO}} / \gamma_{\mathrm{CoO}}$ within the slag were considered likely to remain constant. An isothermally constant distribution coefficient $K_{\gamma}$ could then be defined in terms of the activity coefficient ratio and equilibrium constant $K_{8}$, through rearrangement of Eq. [9] according to:

$$
\left(\frac{\gamma_{\mathrm{Fe}}}{\gamma_{\mathrm{Co}}} \frac{\gamma_{\mathrm{CoO}}}{\gamma_{\mathrm{FeO}}}\right) K_{8}=\left(\frac{x_{\mathrm{Co}}}{x_{\mathrm{CoO}}} \frac{x_{\mathrm{FeO}}}{x_{\mathrm{Fe}}}\right)=\left(\frac{n_{\mathrm{Co}}}{n_{\mathrm{CoO}}} \frac{n_{\mathrm{FeO}}}{n_{\mathrm{Fe}}}\right)=K_{\gamma}
$$

The initial moles of metals and oxides were then, respectively, defined as $n_{\mathrm{Co}}^{o}, n_{\mathrm{Fe}}^{o}, n_{\mathrm{CoO}}^{o}, n_{\mathrm{FeO}}^{o}$ to give the following mass balance and recovery expressions:

$$
\begin{gathered}
n_{\mathrm{Co}}=n_{\mathrm{Co}}^{o}+n_{\mathrm{CoO}}^{o}-n_{\mathrm{CoO}} \\
n_{\mathrm{Fe}}=n_{\mathrm{Fe}}^{o}+n_{\mathrm{FeO}}^{o}-n_{\mathrm{FeO}} \\
n_{\mathrm{CoO}}=\left(1-R_{\mathrm{Co}}\right)\left(n_{\mathrm{Co}}^{o}+n_{\mathrm{CoO}}^{o}\right) \\
n_{\mathrm{FeO}}=\left(1-R_{\mathrm{Fe}}\right)\left(n_{\mathrm{Fe}}^{o}+n_{\mathrm{FeO}}^{o}\right)
\end{gathered}
$$

Substitution for $n_{\mathrm{Co}}, n_{\mathrm{CoO}}, n_{\mathrm{Fe}}$ and $n_{\mathrm{FeO}}$ (Eqs. [11] to [14]) within the distribution coefficient expression (Eq. [10]), with rearrangement, then yielded the recovery equation (Eq. [7]).

Since $y$ in the single stage Grimsey equation (Eq. [1]) represents the fraction of iron reporting to slag, the fractional recovery of iron to alloy in the Jones equation $\left(R_{\mathrm{Fe}}\right)$ can be replaced by $1-y$. Substitution for $R_{\mathrm{Fe}}$ in the Jones equation (Eq. [7]) gives:

$$
\begin{aligned}
R_{M e} & =\frac{K_{\gamma} R_{F e}}{1-\left(1-K_{\gamma}\right) R_{F e}}=\frac{K_{\gamma}(1-y)}{1-\left(1-K_{\gamma}\right)(1-y)} \\
& =\frac{K_{\gamma}(1-y)}{(1-y) K_{\gamma}+y}=\frac{1-y}{1-y+\frac{y}{K_{\gamma}}}
\end{aligned}
$$

Thus, the Jones equation takes the same form as the single stage Grimsey equation; further, the equations are mathematically identical since $K_{\gamma}=K_{M e}^{\prime}$ according to: 
$K_{\gamma}=\frac{n_{M e}}{n_{M e O}} \frac{n_{F e O}}{n_{F e}}=\frac{\left[n_{M e}\right]}{\left(n_{M e}\right)} \frac{\left(n_{F e}\right)}{\left[n_{F e}\right]}=\frac{[M e p c t]}{(\text { Mepct })} \frac{(F e p c t)}{[F e p c t]}=K_{M e}^{\prime}$

The Jones equation can also be derived if $(1-y)$ in the single stage Grimsey equation is replaced by $R_{F e}$. As a result, the $R_{M e}$ versus $R_{F e}$ figures presented by Jones et al. ${ }^{[6-11]}$ are mirror images of the $R_{M e}$ versus $y$ figures presented by Grimsey ${ }^{[1-4]}$ and the concepts discussed are similar.

Significantly, when Eqs. [10] to [14] are combined in the Jones derivation to yield Eq. [7], the result, in common with Eq. [1], is simply a unique expression of the mass balance. Thus, the underlying validity of Jones equation has no dependence on thermodynamics and it is coincidental that the divalent equilibrium constant chosen for the derivation gave the same distribution coefficient as that required by the mass balance.

Consider, for example, the outcome if a monovalent rather than a divalent $\mathrm{Me}$ /iron exchange equilibrium was chosen to define a constant distribution coefficient $K_{v}^{*}$ for the recovery equation. For a monovalent $\mathrm{Me}$ /iron exchange, the distribution coefficient based on the equilibrium constant would take the form:

$$
\begin{aligned}
K_{\gamma}^{*} & =\frac{x_{\mathrm{Me}}^{2}}{x_{\mathrm{Me} 2} \mathrm{O}} \frac{x_{\mathrm{FeO}}}{x_{\mathrm{Fe}}} \cong 2 x_{\mathrm{Me}}\left(\frac{x_{\mathrm{Me}}}{x_{\mathrm{MeO}}} \frac{x_{\mathrm{FeO}}}{x_{\mathrm{Fe}}}\right) \\
& =2 x_{\mathrm{Me}}\left(\frac{n_{\mathrm{Me}}}{n_{\mathrm{MeO}}} \frac{n_{\mathrm{FeO}}}{n_{\mathrm{Fe}}}\right)=2 x_{\mathrm{Me}} K_{\gamma}
\end{aligned}
$$

Here $K_{\gamma}$ is the distribution coefficient ultimately required in the recovery equation to meet the mass balance. Thus, when Eqs. [11] to [14] are substituted into Eq. [17] and rearranged, the derived equation would be identical to Eq. [7] except that $K_{\gamma}$ would be replaced by $K_{\gamma}^{*} / 2 x_{M e}$. Clearly, if $K_{\gamma}^{*}$ remains constant, the distribution coefficient $K_{\gamma}$ mandated by the mass balance, will vary as the mole fraction of $M e$ in the alloy changes during the process. A similar outcome will result if a trivalent metal exchange is used as a template to identify a constant distribution coefficient.

Thus, based on its derivation, the Jones equation strictly only applies to divalent metals which equilibrate with iron through a dominant exchange reaction. An additional limitation is that the metal must predominantly be dissolved rather than mechanically entrained within slag such that an equilibrium constant can determine the distribution. However, notwithstanding these constraints, Jones et al ${ }^{[9]}$ have reasonably fitted the recoveries of $\mathrm{Co}, \mathrm{Ni}, \mathrm{Cr}$ and PGM's within oxide reduction systems using constant $K_{y}$ values.

Originally, Eq. [1] was developed and utilized within an industry and government co-sponsored project ${ }^{[1]}$ aimed at understanding the recovery of cobalt within the Kalgoorlie Nickel Smelter using both laboratory and plant data. A major outcome of the study was the recognition that cobalt recovery could be monitored, controlled and optimized through consideration of iron transfer as summarized within Eq. [1]. The concept was subsequently used for the simulation of $\mathrm{Ni}, \mathrm{Co}$ and $\mathrm{Cu}$ recoveries within an industrial Peirce Smith converter operation which involved significant iron transfer from matte to slag. ${ }^{[5]}$

The industrial significance of Eq. [1], however, extends beyond its application to nickel smelting and converting, firstly because it can potentially be applied to a range of other separation processes as initially discussed, and secondly because it likely supports valuable industrial guidelines for the monitoring and optimization of metal recovery within other non-ferrous smelting processes. These are processes where iron is a major impurity and where the non-ferrous metal oxide is less stable than ferrous oxide, (i.e., $K_{M e}^{\prime}>1$ ) such that Fe can be preferentially oxidized compared to $M e$ to affect separation.

The application of Eq. [1] to nickel smelting and converting processes has highlighted the following guidelines for managing non-ferrous metal recovery:

(1) The so-called $L_{M e}$ ratio, where $L_{M e}=\frac{[M e p c t]}{(M e p c t)}$, has been commonly used as an indicator of metal recovery performance, but Eq. [1] shows that

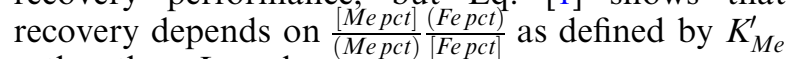
rather than $L_{M e}$ alone.

2) It is generally considered that increase in slag mass through addition of fluxes for liquidus or viscosity control will decrease metal recovery; however, a mass increase alone will not change the ratio of dissolved metals $\frac{(F e p c t)}{(M e p c t)}$ or $K_{M e}^{\prime}$ and affect metal recovery, except in the presence of significant acid-base interactions (discussed below).

3) Processes with larger $K_{M e}^{\prime}$ values at a given fractional iron transfer $y$, will give higher, but not proportionally higher recoveries of $M e$; i.e., process recoveries cannot be directly compared using $K_{M e}^{\prime}$ values.

4) Eq. [1] quantifies the well-understood concept that recovery of $M e$ with a defined end-point iron content (i.e., with fixed $[\mathrm{Fe} \mathrm{pct}]$ ), will decrease with increase in $\mathrm{Fe} / \mathrm{Me}$ in feed, or with any downstream addition of iron, since both will increase the iron transfer required to achieve the end point.

5) It follows from (4), that a fair comparison of non-ferrous metal recovery within two different processes or flowsheets can only be made at a point where the fractional iron transfer is the same for both.

6) It is well understood that as iron transfer approaches the end point, the recovery of non-ferrous metal decreases more rapidly. This is reflected within Eq. [1], since with $K_{M e}^{\prime}>1$, the recovery of $M e$ falls at an increasing rate as the fractional iron transfer to slag increases. This can be shown from the derivative of Eq. [1], with the fall increasing very rapidly after $y$ exceeds $\sim 0.9$. However, the recovery of $M e$ can be increased if iron is transferred in a series of steps as achieved using Peirce Smith Converters. In this case, Eq. [6] can be used with Solver in Excel to vary the $y$ 's to maximize $R_{M e}$, subject to process constraints. Further, if $K_{M e}^{\prime}$ is constant, as for $\mathrm{Ni}$ and Co in nickel converting, ${ }^{[5]}{ }^{\mathrm{Me}}$ recovery can be optimized for both metals using the same series of steps. ${ }^{[1]}$ 
Ultimately, the industrial value of $K_{M e}^{\prime}$ can only be obtained by fitting plant data, but the presence of a dominant divalent iron exchange equilibrium can influence the magnitude of $K_{M e}^{\prime}$ and also dictate how change in temperature and addition of flux to slag will affect $K_{M e}^{\prime}$.

The distribution of cobalt within oxidative sulfide matte/slag smelting and converting, for example, is likely controlled by the equilibrium exchange of iron between matte and slag ${ }^{[1-4]}$ according to:

$$
\mathrm{CoS}(\text { matte })+\mathrm{FeO}(\text { slag }) \leftrightarrow \mathrm{CoO}(\text { slag })+\mathrm{FeS}(\text { matte })
$$

for which it is readily shown that:

$$
K_{C o}^{\prime}=\frac{[\text { Copct }]}{(\text { Copct })} \frac{(\text { Fe pct })}{[F e p c t]}=\left(\frac{\gamma_{C o O}}{\gamma_{F e O}} \frac{\gamma_{F e S}}{\gamma_{C o S}}\right) \frac{1}{K_{18}}
$$

where $\gamma$ is the activity coefficient relative to the pure liquid standard state and $K_{18}$ is the equilibrium constant for reaction [18].

Since the exchange reaction [18] is endothermic, the equilibrium constant $K_{18}$ increases with increase in temperature, such that $K_{C o}^{\prime}$ decreases (cf. Eq. [19]) which will also decrease the recovery of cobalt.

The effect of flux addition to slag on cobalt recovery will depend on how the addition affects the $\gamma_{\mathrm{CoO}} / \gamma_{\mathrm{FeO}}$ in slag (cf. Eq. [19]) and not on how it affects $\gamma_{\mathrm{CoO}}$ alone. Experimental data ${ }^{[1]}$ show that the value of $\gamma_{\mathrm{CoO}}$ is increased by addition of $\mathrm{MgO}, \mathrm{Al}_{2} \mathrm{O}_{3}$ and $\mathrm{CaO}$ in slag and decreased by the addition of $\mathrm{SiO}_{2}$ due to acid-base interactions. However, the $\gamma_{\mathrm{CoO}} / \gamma_{\mathrm{FeO}}$ ratio remains relatively constant with addition of $\mathrm{MgO}$ and $\mathrm{Al}_{2} \mathrm{O}_{3}$, decreases slightly with $\mathrm{CaO}$ addition, and increases with $\mathrm{SiO}_{2}$ addition. ${ }^{[1]}$ On this basis, increases of $\mathrm{MgO}$ and $\mathrm{Al}_{2} \mathrm{O}_{3}$ in slag should not significantly affect cobalt recovery; however, increase in $\mathrm{CaO}$ should slightly decrease the recovery, and increase in $\mathrm{SiO}_{2}$ should increase it.

In summary, a novel recovery equation developed to describe non-ferrous metal recovery from sulfide smelting and converting processes is shown to provide a valuable template for the assessment and monitoring of non-ferrous metal recovery as a function of iron transfer, through use of an easily measured distribution coefficient. Since the equation is derived from a mass balance without any thermodynamic restrictions, it would be applicable to any two-phase separation process in which the recovery of one species can be related to that of another. A similar equation, subsequently developed to describe non-ferrous metal recovery from reduction smelting, is shown to be mathematically identical to the single stage version of the original equation. However, it was derived using thermodynamic considerations which appear to validate its use only for divalent metals which give constant distribution coefficients.

\section{OPEN ACCESS}

This article is licensed under a Creative Commons Attribution 4.0 International License, which permits use, sharing, adaptation, distribution and reproduction in any medium or format, as long as you give appropriate credit to the original author(s) and the source, provide a link to the Creative Commons licence, and indicate if changes were made. The images or other third party material in this article are included in the article's Creative Commons licence, unless indicated otherwise in a credit line to the material. If material is not included in the article's Creative Commons licence and your intended use is not permitted by statutory regulation or exceeds the permitted use, you will need to obtain permission directly from the copyright holder. To view a copy of this licence, visit http://creativec ommons.org/licenses/by/4.0/.

\section{REFERENCES}

1. E.J. Grimsey: Report 92 (115 p), Mineral Research Institute of Western Australia, May 1992. (available on request e.grimsey@curtin.edu.au).

2. E.J. Grimsey: Proceedings of Extractive Metallurgy of Gold and Base Metals, AusIMM (Melbourne), 1992, pp. 471-75.

3. E.J. Grimsey: Proceeding of the Paul E. Queneau Symposium "Extractive Metallurgy of Copper, Nickel and Cobalt, vol. 1: Fundamental Aspects (Eds R.G. Reddy and R.N. Weizenbach), TMS-AIME (Warrendale, PA), 1993, pp. 1239-51.

4. E.J. Grimsey: AusIMM Proc., 1994, vol. 209 (2), pp. 77-80.

5. E.J. Grimsey, B.P. Tran, M.J. Tjerkstra and S.A. Messner: Simulation of a Nickel Converter using a Metal Recovery Equation, TMS annual conference, 1994 (available on request e.grimsey@curtin.edu.au).

6. R.T. Jones, G.M. Denton, Q.G. Reynolds, J.A.L. Parker and G.J.J. van Tonder: J. South. Afr. Inst. Min. Metall., 2002, 102(1), pp. 5-9.

7. S.D. McCullough, I.J. Geldenhuys and R.T. Jones: 3rd International Platinum Conference 'Platinum in Transformation', 2008, pp. 169-76.

8. I.J. Geldenhuys and R.T. Jones: Proceedings 48th Conference of Metallurgists of CIM, 2009, pp. 415-27.

9. R.T. Jones, I.J. Geldenhuys, and Q.G. Reynolds: J. South. Afr. Inst. Min. Metall., 2009, vol. 109 (10), pp. 587-92.

10. R.T. Jones: Proceedings of EMC, 2013, pp. 1109-25.

11. R.T. Jones and C. Pawlik: Proceedings of the 58th Conference of Metallurgists, 2019, paper 592323.

12. M. Lucas: Maths and Physical Sciences, Murdoch University, WA, unpublished work, Perth, 1992.

Publisher's Note Springer Nature remains neutral with regard to jurisdictional claims in published maps and institutional affiliations. 